\title{
Genotyping of Giardia duodenalis from Southern Brown Howler Monkeys (Alouatta clamitans) from Brazil
}

\author{
A.C.C. Volotão ${ }^{\text {a,b }}$, J.C. Souza Júnior ${ }^{c}$, C. Grassini ${ }^{a}$, J.M. Peralta ${ }^{b}$, O. Fernandes ${ }^{\text {a,* }}$ \\ ${ }^{a}$ Laboratório de Epidemiologia Molecular de Doenças Infecciosas, Instituto Oswaldo Cruz - Fundação Oswaldo Cruz, \\ Av. Brasil, 4365, Manguinhos, Rio de Janeiro, RJ 21045-090, Brazil \\ ${ }^{\mathrm{b}}$ Departamento de Imunologia, Instituto de Microbiologia Professor Paulo de Góes, Universidade Federal do Rio de Janeiro, \\ Rio de Janeiro, RJ 21.941-590, Brazil \\ ${ }^{\mathrm{c}}$ Centro de Pesquisas Biológicas e Observatório de Primatas de Indaial - CEPESBI, Indaial, SC 88.130-000, Brazil \\ Received 16 October 2007; received in revised form 1 July 2008; accepted 7 July 2008
}

\begin{abstract}
Giardia duodenalis is a widespread intestinal protozoan that can infect humans and animals, both domestic and wild. Independent of host, infections present with the same symptoms. However, based on host specificity, Giardia isolates have been grouped into genotypes A to G. Parasites of assemblage A and B are known to infect humans, in addition to primates and a wide variety of mammals. In Brazil, hitherto Giardia genotypes were defined only for humans and domestic animals. To evaluate the genotypes of different Giardia present among other animals, fecal samples from 28 Southern Brown Howler Monkeys (Alouatta clamitans) kept in captivity from South Brazil were screened for $G$. duodenalis using parasitological methods. All of them were asymptomatic, but positive for Giardia. The genotype of the G. duodenalis circulating among these animals was ascertained by molecular typing, performed using amplification and sequencing of the $\beta$-giardin gene. Sixteen of 28 samples were successfully amplified by PCR and sequencing of this gene s revealed that all of them were of the genotype A1. These findings suggest that A. clamitans represent a potential risk of environmental contamination of a $G$. duodenalis genotype that also infect humans, and therefore can be considered a potential reservoir for $G$. duodenalis of a genotype that can also infects humans. Therefore, these results highlight a potential public health problem due to the epidemiological and molecular evidence for anthropozoonotic transmission.
\end{abstract}

(C) 2008 Elsevier B.V. All rights reserved.

Keywords: Giardia duodenalis; Alouatta clamitans; Genotyping; $\beta$-Giardin; Anthropozoonosis

\section{Introduction}

Giardia duodenalis (syn. G. intestinalis, G. lamblia) is a protozoa that often infects vertebrates relevant to evolutionary and medical studies. Its life cycle consists of two stages: cysts that are responsible for the fecal-oral transmission and trophozoites that establish infection

\footnotetext{
* Corresponding author. Tel.: +55 212280 3740; fax: +55212280 3740 .

E-mail address: octaviofernandes@ fiocruz.br (O. Fernandes).
}

within animal host's duodenum (Thompson, 1994). Phylogenic analyses of different loci have ordered $G$. duodenalis on one of the earliest diverging eukaryotic lineages (Boothroyd et al., 1987; Edlind and Chakraborty, 1987; Sogin et al., 1989; Hashimoto et al., 1994; Okamoto and Hasegawa, 1995; Adam, 2001). This parasite is responsible for causing approximately 1 billion cases of diarrheal disease annually worldwide (Islam, 1990; WHO/UNICEF, 2000) and about 2.5 million annual infections in the United States (Furness et al., 2000). It also is a significant veterinary pathogen (USDA, 1994). 
Although G. duodenalis isolates from different host species are morphologically indistinguishable, they have been grouped into of seven genetically distinct genotypes (Monis et al., 2003). Genotypes A and B have been detected in humans and in a wide range of other mammals, while $\mathrm{C}$ to $\mathrm{G}$ appear to be restricted from humans as hosts. Genotypes A and B infect other primates than humans such mountain gorillas (Gorilla gorilla berengei) (Graczyk et al., 2002), Black howler Monkeys (Alouatta pigra) (Vitazkova and Wade, 2006) and have also been found in other domestic and wild animals, such as dogs, cats, cattle, pigs, slow loris, siamang, beavers and white tailed deer, suggesting that genotypes $\mathrm{A}$ and $\mathrm{B}$ demonstrate a zoonotic preference (Thompson, 2000; Thompson and Monis, 2004; Cacciò et al., 2005; Hunter and Thompson, 2005; Volotão et al., 2007).

The howler monkeys (genus Alouatta monotypic in subfamily Alouattinae) are among the largest of the New World monkeys. In Brazil, ten species are currently recognized. One of these, Alouatta clamitans (Gregorim, 2006), is native to South and Central American forests. The knowledge of the parasitic diseases that can infect humans carried among these monkeys and others will have an impact on human health and species conservation. To date, no genotyping studies using stocks from monkeys have been carried out in Brazil. The present study was conducted to determine the genotypes of isolates of $G$. duodenalis shed by Southern Brown Howler Monkeys (A. clamitans) from South of Brazil using $\beta$-giardin gene as a target.

\section{Materials and methods}

\subsection{Sampling}

Fecal samples of 28 A. clamitans kept in captivity $(N=28)$ were collected between April 2005 and April of 2006 in order to investigate the presence of $G$. duodenalis. The samples were collected directly from the rectum of each by their veterinarians. These animals were kept in captivity in Centro de Pesquisas Biológicas e Observatório de Primatas de Indaial, CEPESBI, Blumenau, Santa Catarina, Southern Brasil $\left(26^{\circ} 54^{\prime} \mathrm{S}\right.$ and $\left.49^{\circ} 13^{\prime} \mathrm{W}\right)$. The research described herein was previously approved by the Ethics Committees of the Regional University of Blumenau (033/04).

\subsection{Diagnosis and isolation}

Fecal samples were examined for $G$. duodenalis at Laboratory of Parasitology, Regional University of
Blumenau. The samples were analyzed by microscopy (Faust et al., 1939) and kept under refrigeration until genotyping. One positive sample from each animal was stored in new vials and transported under refrigeration to the Laboratory of Molecular Epidemiology and Infectious Diseases in Oswaldo Cruz Institute, Fiocruz, Rio de Janeiro, RJ. Cysts were purified approximately 6 months after collection by sucrose density gradient centrifugation as previously described (Maddox-Hyttel et al., 2006).

\subsection{Molecular characterization}

Total DNA from G. duodenalis cysts was extracted using a commercial kit (QIAmp DNA Stool Mini Kit, Qiagen GmbH. Germany) according to the manufacture's instructions with minor modifications. Lysis temperature was increased to $95{ }^{\circ} \mathrm{C}$, and the DNA was eluated with $100 \mu \mathrm{L}$ of elution buffer and stored at $4{ }^{\circ} \mathrm{C}$. Polymerase chain reaction (PCR) to amplify fragment of the $\beta$-giardin gene was performed as described (Cacciò et al., 2002). Amplified products were purified using the Wizard ${ }^{\mathbb{R}}$ SV Gel and Pcr Clean-Up System (Promega, Madison, WI, USA). DNA fragments were sequenced in both directions using the ABI Prism ${ }^{\mathrm{TM}}$ BigDye Terminator Cycle Sequencing kit (Applied Biosystems, Foster City, CA) on an ABI 3730 automatic DNA sequencer (Applied Biosystems, Foster City, CA).

Sequences were analyzed using Chromas (http:// www.technelysium.com.au/chromas.html) and compared with known Giardia spp. sequences obtained from GenBank using ClustalW algorithm (Thompson, 1994) in the MEGA version 4.0 (http://www.megasoftware.net). Phylogenetic analyses of 328 nucleotides length $\beta$-giardin sequences were performed through MEGA 4.0, on alignments obtained from ClustalW. The distance estimations were carried out using Jin and $\mathrm{Nei}$ (1990) equation (Kimura two-parameter model). The phylogenetic trees were constructed using a neighborjoining algorithm (Saitou and Nei, 1987). For each calculation, branch reliability was assessed using bootstrap analysis (1000 replicates). A reference $\beta$ giardin gene sequence representing each major $G$. duodenalis genotypes (GenBank accession numbers listed in Fig. 1) was aligned against the sequences obtained from the new isolates. The nucleotide sequence of $\beta$-giardin from $G$. muris (GenBank accession number AY258618) was used as an outgroup.

\subsection{Nucleotide sequence accession numbers}

The new nucleotide sequences were deposited in the GenBank database under accession numbers 


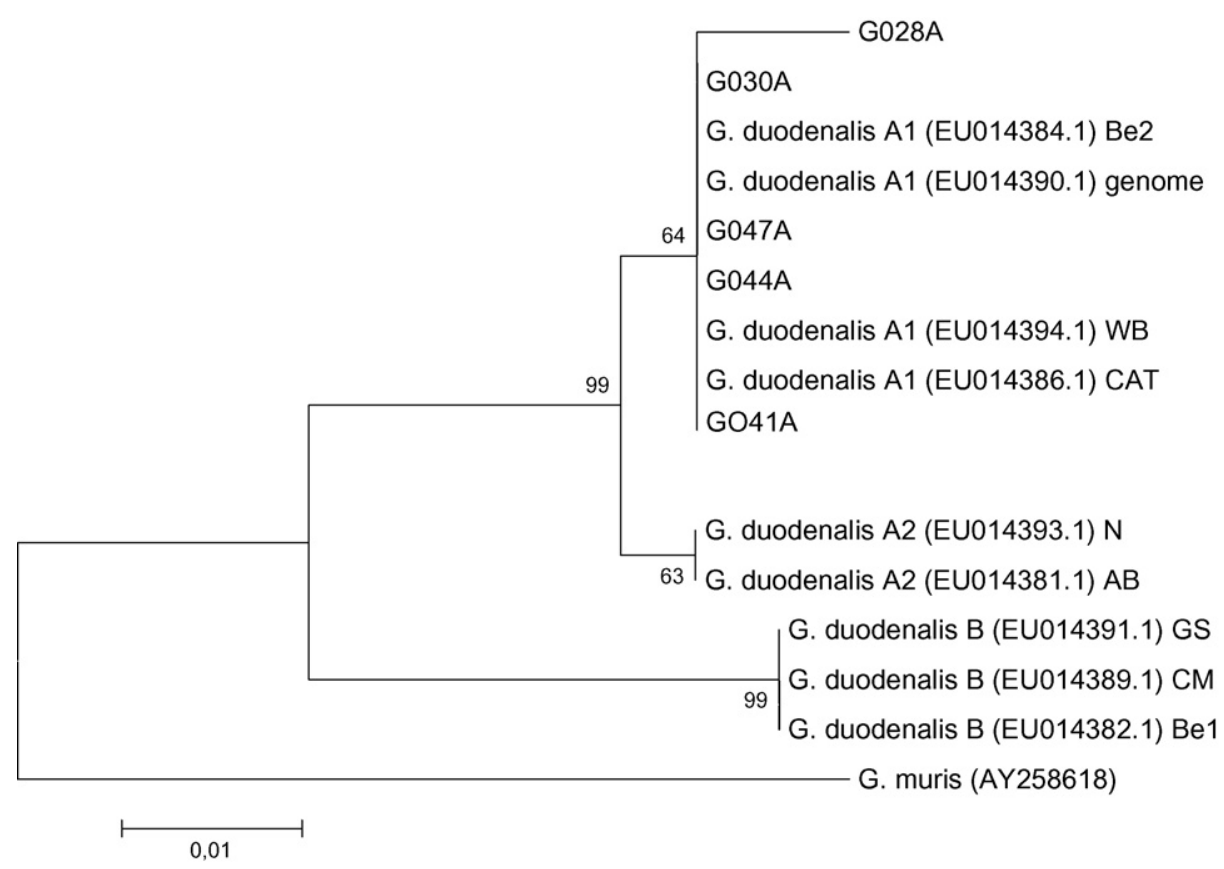

Fig. 1. Neighbor-joining phylogenetic analyses of G. duodenalis isolates from A. clamitans at beta giardin loci, carried out using the Kimura twoparameter model.

EU200933-EU200937 corresponding to partial $G$. duodenalis $\beta$-giardin sequences from five Alouatta clamitans isolates.

\section{Results}

This group of monkeys all tested positive for Giardia infection at least once during the timeframe of this project (April 2005-April 2006). One positive sample from each Southern Brown Howler Monkeys (Alouatta clamitans) was used for cyst purification, DNA extraction and genotyping of $G$. duodenalis isolates. Sixteen out of the 28 samples collected yielded amplified products using the $\beta$-giardin primers. Sequence analysis of a $328 \mathrm{bp} \beta$-giardin fragment of these isolates suggested that all of them were $G$. duodenalis genotype A1 (Fig. 1). Fifteen out of the sixteen sequences were homologous and one amplified product (G028A sample - accession number EU200933) revealed three single nucleotide polymorphisms (SNPs) that are not known to be present in the prototype A1 (reference sequence - EU014394.1) (Fig. 1). All of the SNPs are transitions and two of them cause a conversion of the amino acid (A53V and $\mathrm{R} 221 \mathrm{H}$ ). Our results showed that the SNPs in $\beta$-giardin sequence from sample G028A (accession number EU200933) are unique and have not been described so far in samples belonging to genotypes $\mathrm{A}$.

\section{Discussion}

Little information is available regarding G. duodenalis genotypes in wildlife, although genotype $\mathrm{A}$ is the most prevalent. Several sylvan hosts have been identified bearing this genotype on different continents: gorillas (Africa), deers and moose (North America and Europe), kangaroos and fox (Australia) (Graczyk et al., 2002; Trout et al., 2003; van der Giessen et al., 2006; Lalle et al., 2007; Robertson et al., 2007; McCarthy et al., 2008). This is the first description of this genotype in Southern Brown Howler Monkeys (A. clamitans). This genotype is widespread worldwide (Cacciò et al., 2005) and has been previously detected in Brazil in humans and domestic animals (Volotão et al., 2007).

The amplification of the $\beta$-giardin gene by PCR directly from cysts has been used previously to genotype G. duodenalis (Cacciò et al., 2002; EligioGarcia et al., 2005; Lalle et al., 2005a,b; Volotão et al., 2007). Among the 28 samples that tested positive for $G$. duodenalis according to microscope examination, 16 yielded PCR products for the $\beta$-giardin gene. For the other 12, it is possible that the load of G. duodenalis in the sample was insufficient for PCR amplification since cysts are shed intermittently.

The A. clamitans screened in this study were kept in captivity in an area surrounded by human dwellings. Indeed, the monkeys were in direct contact with 
domestic cats, which eventually began circulating through the cages. This continual contact could create a link between monkeys and humans within the peridomestic setting developed by the cats. Considering that monkeys and humans are both infected by the same genotypes of $G$. duodenalis, there is a potential public health risk for the traffic of $G$. duodenalis cysts to humans (Macpherson, 2005; Papini et al., 2007; Volotão et al., 2007).

Other hypothesis for the presence of $G$. duodenlais in these monkeys could be (i) the contact of the monkeys with other wildlife animals that live nearly in a fragment of the forest and circulate near human dwellings, such as opossums. This hypothesis is strengthened by the fact that Southern Brown Howler Monkeys in the wild environment have been found infected with Giardia within the same geographical area (Müller et al., 2000) and (ii) the transmission of these genotypes by humans who have contact with these monkeys, such as Biologists and Veterinarians.

One of the 16 sequenced samples showed a distinct $\beta$-giardin sequence from genotype A1 (EU014394.1) with three specific SNPs that have not been described previously. All of them are transitions, but two of these are in the second codon position altering the primary structure of the codified protein, changing an alanin to valine and an arginine to a histidine. It is important to note that both have the same biochemical features. The genetic similarities between $G$. duodenalis isolates from humans and other primates as $A$. clamitans suggest epidemiological and molecular evidence of occurrence of anthropozoonotic transmission. The high prevalence of $G$. duodenalis and its asymptomatic feature demonstrates that $A$. clamitans represent a potential risk for environmental contamination and can be considered a potential public health problem.

Increasing the typing resolution and further molecular epidemiological studies of giardiasis in humans using case-control study design and subtyping analysis of specimens from both humans and animals are needed to provide more evident conclusions whether the human A1 infections are results of anthroponotic or zoonotic transmission.

\section{Acknowledgments}

We are particularly grateful to Dr. Juliane Araújo Greinert, of the Laboratory of Parasitology of Regional University of Blumenal (FURB), for kindly performing the parasitological exam.

\section{References}

Adam, R.D., 2001. Biology of Giardia lamblia. Clin. Microbiol. Rev. 14, 447-475.

Boothroyd, J.C., Wang, A., Campbell, D.A., Wang, C.C., 1987. An unusually compact ribosomal DNA repeat in the protozoan Giardia lamblia. Nucleic Acids Res. 15, 4065-4084.

Cacciò, S., De Giacomo, M., Pozio, E., 2002. Sequence analysis of the $\beta$-giardin gene and development of a polymerase chain reactionrestriction fragment length polymorphism assay to genotype Giardia duodenalis cysts from human faecal samples. Int. J. Parasitol. 32, 1023-1030.

Cacciò, S.M., Thompson, R.C., McLauchlin, J., Smith, H.V., 2005. Unravelling Cryptosporidium and Giardia epidemiology. Trends Parasitol. 21, 430-437.

Edlind, T.D., Chakraborty, P.R., 1987. Unusual ribosomal RNA of the intestinal parasite Giardia lamblia. Nucleic Acids Res. 15, 78897901.

Eligio-Garcia, L., Cortes-Campos, A., Jimenez-Cardoso, E., 2005. Genotype of Giardia intestinalis isolates from children and dogs and its relationship to host origin. Parasitol. Res. 97, 1-6.

Faust, E.C., Sawits, W., Tobie, J., 1939. Comparative efficiency of various techniques for the diagnosis of protozoa and helminths in feces. J. Parasitol., Lawrence 25, 241-262.

Furness, B.W., Beach, M.J., Roberts, J.M., 2000. Giardiasis surveillance-United States, 1992-1997. Morb. Mortal. Wkly. Rep. 49, $1-13$.

Graczyk, T.K., Bosco-Nizeyi, J., Ssebide, B., Thompson, R.C., Read, C., Cranfield, M.R., 2002. Anthropozoonotic Giardia duodenalis genotype (assemblage) a infections in habitats of free-ranging human-habituated gorillas, Uganda. J. Parasitol. 88, 905-909.

Gregorim, R., 2006. Taxonomy and geographic variation of genus Alouatta Lacépède (Primates, Atelidae) in Brasil. Revista Brasileira de Zoologia 23, 1.

Hashimoto, T., Nakamura, Y., Nakamura, F., Shirakura, T., Adachi, J., Goto, N., Okamoto, K., Hasegawa, M., 1994. Protein phylogeny gives a robust estimation for early divergences of eukaryotes: phylogenetic place of a mitochondria-lacking protozoan, Giardia lamblia. Mol. Biol. Evol. 11, 65-71.

Hunter, P.R., Thompson, R.C., 2005. The zoonotic transmission of Giardia and Cryptosporidium. Int. J. Parasitol. 35, 1181-1190.

Islam, A., 1990. Giardiasis in developing countries. In: Myer, E.A. (Ed.), Giardiasis. Elsevier, Amsterdam, The Netherlands, pp. 235-266.

Jin, L., Nei, M., 1992. Limitations of the evolutionary parsimony method of phylogenetic analysis. Mol. Biol. Evol. 7, 82-102 (Erratum in: Mol. Biol. Evol. 1990 7, 201).

Lalle, M., Pozio, E., Capelli, G., Bruschi, F., Crotti, D., Cacciò, S.M., 2005a. Genetic heterogeneity at the $\beta$-giardin locus among human and animals isolates of Giardia duodenalis and identification of potentially zoonotic genotypes. Int. J. Parasitol. 35, 207-213.

Lalle, M., Jimenez-Cardosa, E., Cacciò, S.M., Pozio, E., 2005b. Genotyping of Giardia duodenalis from humans and dogs from Mexico using a $\beta$-giardin nested polymerase chain reaction assay. J. Parasitol. 91, 203-205.

Lalle, M., Frangipane di Regalbono, A., Poppi, L., Nobili, G., Tonanzi, D., Pozio, E., Cacciò, S.M., 2007. A novel Giardia duodenalis assemblage A subtype in fallow deer. J. Parasitol. 93, 426-428.

Macpherson, C.N., 2005. Human behaviour and the epidemiology of parasitic zoonoses. Int. J. Parasitol. 35, 1319-1331. 
Maddox-Hyttel, C., Langkjær, R.B., Enemark, H.L., Vigre, H., 2006. Cryptosporidium and Giardia in different age groups of Danish cattle and pigs-Occurrence and management associated risk factors. Vet. Parasitol. 141, 48-59.

McCarthy, S., Ng, J., Gordon, C., Miller, R., Wyber, A., Ryan, U.M., 2008. Prevalence of Cryptosporidium and Giardia species in animals in irrigation catchments in the southwest of Australia. Exp. Parasitol. 118, 596-599.

Monis, P.T., Andrews, R.H., Mayrhofer, G., Ey, P.L., 2003. Genetic diversity within the morphological species Giardia intestinalis and its relationship to host origin. Infect. Genet. Evol. 3, 29-38.

Müller, G.C.K., Krambeck, A., Hirano, Z.N.B., Silva Filho, H.H., 2000. Levantamento preliminar de endoparasitas em bugios Alouatta clamitans. Neotrop. Primates 8, 107-108.

Okamoto, Hasegawa, M., 1995. Phylogenetic place of mitochondrion lacking protozoan, Giardia lamblia, inferred from amino acid sequences of elongation factor 2. Mol. Biol. Evol. 12, 782-793.

Papini, R., Cardini, G., Paoletti, B., Giangaspero, A., 2007. Detection of Giardia assemblage A in cats in Florence, Italy. Parasitol. Res. 100, 653-656.

Robertson, L.J., Forberg, T., Hermansen, L., Hamnes, I.S., Gjerde, B., 2007. Giardia duodenalis cysts isolated from wild moose and reindeer in Norway: genetic characterization by PCR-rflp and sequence analysis at two genes. J. Wildl. Dis. 43, 576-585.

Saitou, N., Nei, M., 1987. The neighbor-joining method: a new method for reconstructing phylogenetic trees. Mol. Biol. Evol. 4, 406-425.

Sogin, M.L., Gunderson, J.H., Elwood, H.J., Alonso, R.A., Peattie, D.A., 1989. Phylogenetic meaning of the kingdom concept: an unusual ribosomal RNA from Giardia lamblia. Science 243, 7577.

Thompson, R.C., 1994. Giardia lamblia in children and the child care setting: a review of the literature. J. Ped. Child Health 30, 202209.

Thompson, R.C.A., 2000. Giardiasis as a re-emerging infectious disease and its zoonotic potential. Int. J. Parasitol. 30, 1259-1267.

Thompson, R.C., Monis, P.T., 2004. Variation in Giardia: implications for taxonomy and epidemiology. Adv. Parasitol. 58, 69-137.

Trout, J.M., Santin, M., Fayer, R., 2003. Identification of assemblage A Giardia in white-tailed deer. J. Parasitol. 89, 1254-1255.

USDA, 1994. Cryptosporidium and Giardia in Beef Calves. Beef Cow/ Calf Health and Productivity Audit. National Animal Health Monitoring System, USDA, Washington, DC.

van der Giessen, J.W., de Vries, A., Roos, M., Wielinga, P., Kortbeek, L.M., Mank, T.G., 2006. Genotyping of Giardia in Dutch patients and animals: a phylogenetic analysis of human and animal isolates. Int. J. Parasitol. 36, 849-858.

Vitazkova, S.K., Wade, S.E., 2006. Parasites of free-ranging black howler monkeys (Alouatta pigra) from Belize and Mexico. Am. J. Primatol. 68, 1089-1097.

Volotão, A.C., Costa-Macedo, L.M., Haddad, F.S., Brandão, A., Peralta, J.M., Fernandes, O., 2007. Genotyping of Giardia duodenalis from human and animal samples from Brazil using beta-giardin gene: a phylogenetic analysis. Acta Trop. 102, 1019.

WHO/UNICEF, 2000. Global water supply and sanitation assessment 2000 report. WHO/UNICEF Joint Monitoring Programme for Water Supply and Sanitation. WHO, Geneva, Switzerland. 